\title{
Signal of proteinase-activated receptor-2 contributes to highly malignant potential of human pancreatic cancer by up-regulation of interleukin-8 release
}

\author{
OSAMU IKEDA, HIROSHI EGAMI, TAKATOSHI ISHIKO, SHINJI ISHIKAWA, \\ HIDENOBU KAMOHARA, HIDEKI HIDAKA, MASAHUMI TAKAHASHI and MICHIO OGAWA \\ Department of Gastroenterological Surgery, Postgraduate School of Medical Sciences, \\ Kumamoto University, 1-1-1 Honjo, Kumamoto City 860-8556, Japan
}

Received November 4, 2005; Accepted December 19, 2005

\begin{abstract}
Proteinase-activated receptor-2 (PAR-2) is expressed in various tissues, including cancer lesions. However, the functional consequences of PAR-2 expression in cancer cells, especially in pancreatic cancer cells, are poorly understood. To clarify the biological significance of PAR-2 signaling in pancreatic cancer, we examined the production of growth factors and cytokines, such as IL-6, IL-8, bFGF, TGF-ß1, and VEGF, by specific ELISAs. Two human pancreatic cancer cell lines, SUIT2 and MiaPaCa2, which have been shown to express PAR-2, were stimulated by trypsin and PAR-2 activating peptide (PAR-2AP: SLIGKV-NH $\mathrm{N}_{2}$ ). After $24 \mathrm{~h}$, the culture supernatants were collected and specific ELISAs were performed. Although no significant changes were observed in the release of IL-6, bFGF, TGF- 31 , or VEGF, that of IL-8 was significantly up-regulated by PAR-2 agonists in a dose-dependent manner. In addition, IL- 8 receptor expression was found in pancreatic cancer cells and fibroblasts. These results suggest that the PAR-2 signal up-regulates IL-8 release from pancreatic cancer cells. This up-regulated IL-8 has an effect on the pancreatic cancer cells in an autocrine manner and on the fibroblasts in a paracrine manner. Thus, this signal might contribute to tumor progression and characteristic fibrosis in pancreatic cancer.
\end{abstract}

\section{Introduction}

Proteinase-activated receptors (PARs) are G-protein-coupled receptors that are activated by proteolytic cleavage of the extracellular domain, resulting in the generation of a new $\mathrm{N}$ -

Correspondence to: Dr Osamu Ikeda, Department of Gastroenterological Surgery, Postgraduate School of Medical Sciences, Kumamoto University, 1-1-1 Honjo, Kumamoto City 860-8556, Japan

E-mail: ikecho@peace.ocn.ne.jp

Key words: proteinase-activated receptor-2, interleukin-8, pancreatic cancer, fibrosis terminal 'tethered ligand' (1-3). The new N-terminal ligand binds to the core of the receptor and initiates signal transduction resulting in stimulation of phosphoinositide breakdown and cytosolic calcium mobilization (1-3). Four members of the PAR family have been cloned; PAR-1, PAR-3, and PAR-4 can be activated by thrombin, whereas PAR-2 is activated by trypsin, mast cell tryptase, and coagulation factors VIIa and Xa, but not thrombin $(2,4,5)$. Short synthetic peptides (activating peptides) corresponding to the new $\mathrm{N}$-termini exposed after cleavage can selectively activate each receptor and mimic the cellular effects of thrombin or trypsin $(1,6-8)$. The discovery of this unique receptor family has highlighted a new role of proteinases as not only degradative enzymes, but also as signaling molecules

PAR-2 is widely expressed in a variety of tissues, and high levels of its expression have been observed in the gastrointestinal tract $(6,8)$. Furthermore, many previous studies have suggested that PAR-2 plays an important role in imflammatory responses $(9,10)$ and is involved in gastrointestinal functions (8,11-14) and various diseases (15-17). PAR-2 expression has also been demonstrated in human gastric $(18)$, colon $(19,20)$, and pancreatic $(21,22)$ cancer cell lines. In gastric, colon and pancreatic cancer, a PAR-2 signal is involved in cancer cell proliferation $(18-20,22)$. The proliferative effect of the PAR-2 signal is mediated by the MEK-MAP kinase cascade (20). Previously, we reported the expression of PAR-2 in human pancreatic cancer cell lines and pancreatic cancer tissues. Furthermore, we demonstrated significantly elevated levels of PAR-2 expression in tissues showing infiltrative growth and severe fibrosis. Thus, we concluded that the expression of PAR-2 is correlated with cancer invasion and cancer fibrosis (21). However, the function of PAR-2 in pancreatic cancer is still unclear.

In the present study, we examined the relationship between the PAR-2 signal and the production of many growth factors and cytokines, which have been shown to be overexpressed in human pancreatic cancer, to evaluate the biological function of PAR-2 in pancreatic cancer.

\section{Materials and methods}

Reagents. Trypsin was purchased from Sigma Chemical Co. (St. Louis, MO, USA). Peptides corresponding to the tethered 


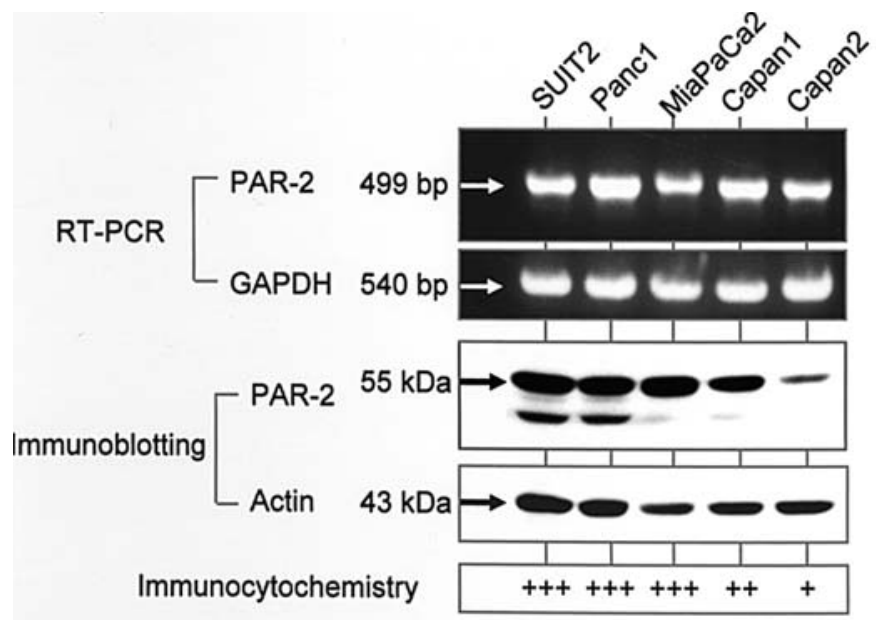

Figure 1. Expression of PAR-2 in human pancreatic cancer cell lines. The expression of PAR-2 in human pancreatic cancer cell lines was analyzed by RT-PCR, Western blot analysis, and immunocytochemical staining. In Western blot analysis, two bands were observed with PAR-2-specific antibody. One with PAR-2-specific molecular weights of $55 \mathrm{kDa}$ was observed in all cancer cell lines, and the other with molecular weights of approximately $50 \mathrm{kDa}$ was observed in SUIT2 and Panc1. The fluorescence intensity of immunocytochemical staining was graded as follows: +++ , strong; ++ , medium; +, weak

ligand of human PAR-2 (PAR-2 activating peptide, PAR-2AP: SLIGKV-NH ${ }_{2}$ ) and the reverse peptide (PAR-2 reverse peptide, PAR-2RP: VKGILS-NH $\mathrm{N}_{2}$ ) were obtained from Kurabo Industries, Ltd. (Osaka, Japan).

Tumor cell lines. The pancreatic cancer cell lines were cultured in RPMI-1640 (Invitrogen Corp., Carlsbad, CA, USA) supplemented with $10 \%$ fetal bovine serum (Invitrogen) at $37^{\circ} \mathrm{C}$ in a $5 \% \mathrm{CO}_{2}$ incubator.

Reverse transcription-polymerase chain reaction (RT-PCR). We investigated PAR-2, trypsinogen, CXC chemokine receptor 1 (CXCR1), and CXCR2 mRNA expression by RT-PCR. Total RNA from human cancer and fibroblast cell lines were extracted by the acid guanidinium-phenolchloroform (AGPC) method using TRIzol (Invitrogen) followed by DNase I digestion to remove genomic DNA. Aliquots of $4 \mu \mathrm{g}$ of total RNA were reverse transcribed with SuperScript ${ }^{\mathrm{TM}}$ First-Strand synthesis system (Invitrogen) using Oligo (dT) primer.

For PCR amplification, the following primer pairs were used: PAR-2, sense primer 5'-GGTAAGGTTGATGGCACA TC-3' and antisense primer 5'-GACCAGCAGAATCAG CAGC-3' (fragment size 499 bp); trypsinogen, sense primer 5'-CCTGATCCTTACCTTTGTGG-3' and antisense primer 5'-GTAGGAGGCTTCACACTTAG-3' (fragment size 514 bp); CXCR1, sense primer 5'-GCTGAAACTGAAGAGGAC AT-3' and antisense primer 5'-CATAGCAAACTGGACTGGAA-3' (fragment size $583 \mathrm{bp}$ ); CXCR2, sense primer 5'-AGGCTTG GAATGTGACTGTG-3' and antisense primer 5'-AGTCCTT TGGCTTCATCGTG-3' (fragment size 501 bp); GAPDH (housekeeping gene), sense primer 5'-GTCAACGGATTTG GTCGTATT-3' and antisense primer 5'-GTCTTCTGGGTG GCAGTGAT-3' (fragment size 540 bp).

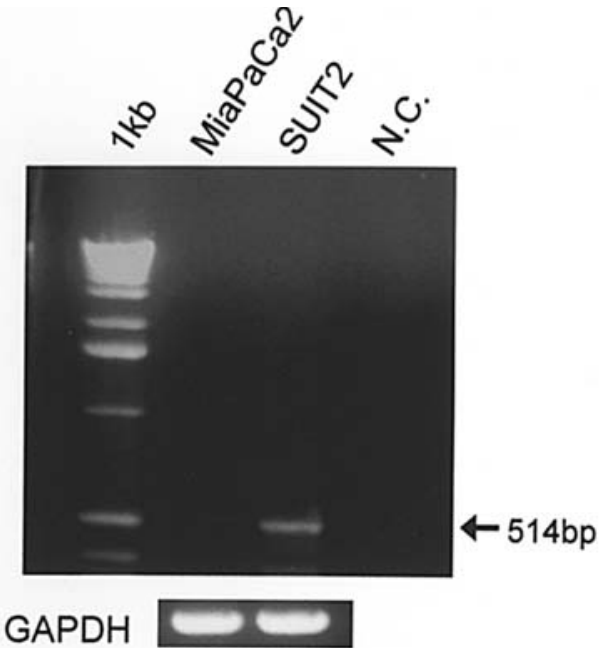

Figure 2. RT-PCR analysis of expression of trypsinogen in SUIT2 and $\mathrm{MiaPaCa} 2$. The expression of trypsinogen in human pancreatic cancer cell lines was analyzed by RT-PCR. Lane 1, 1 kb DNA ladder; lane 2, MiaPaCa2; lane 3, SUIT2; lane 4, negative control.

Immunoblotting. For immunoblotting assay, the cells were harvested from confluent monolayer cultures by incubation in $1.5 \mathrm{mM}$ EDTA in PBS at $37^{\circ} \mathrm{C}$ for $10 \mathrm{~min}$, and pelleted in $1.5 \mathrm{ml}$ microfuge tubes at $1500 \mathrm{rpm}$ for $5 \mathrm{~min}$. The pellets were washed twice in ice-cold PBS and pelleted. The pellets were solubilized in a lysis buffer [10 mM HEPES, pH 7.9; $10 \mathrm{mM} \mathrm{KCl} ; 0.1 \mathrm{mM}$ EDTA; $1.5 \mathrm{mM} \mathrm{MgCl} ; 0.25$ vol\% Nodient-P40; $1 \mathrm{mM}$ DTT, and $0.1 \mathrm{mM}$ phenylmethylsulfonyl fluoride (PMSF)]. After a 5-min incubation on ice, the nuclear pellet was isolated by centrifugation. The supernatant represented the cytoplasmic extract. Equal amounts of proteins were boiled for $5 \mathrm{~min}$ and electrophoresed under reducing conditions on $8 \%(\mathrm{w} / \mathrm{v})$ polyacrylamide gels. Proteins were electrophoretically transferred onto Hybond-ECL membranes (Amersham Biosciences, Tokyo, Japan) and incubated for $8 \mathrm{~h}$ at $4^{\circ} \mathrm{C}$ with primary mouse antibody against human PAR-2 (SAM11) (Santa Cruz Biotechnology, Inc., Santa Cruz, CA, USA) followed by peroxidase-conjugated secondary antibody for $1 \mathrm{~h}$ at room temperature. This antibody (SAM11) was a mouse monoclonal $\mathrm{IgG}_{2 \mathrm{a}}$ antibody raised against amino acids 37-50 (SLIGKVDGTSHVTG) located in the human PAR-2 cleavage site. The Amersham ECL chemiluminescent Western blotting system (Amersham) was used to detect binding of the secondary antibody.

Immunocytochemistry. Pancreatic cancer cell lines were cultured in the wells of four-chamber slides for immunostaining. After reaching confluence, the cells were washed with PBS. The cells were fixed with $2 \%$ formaldehyde and $2 \%$ sucrose/PBS at room temperature for $30 \mathrm{~min}$ and permeabilized with $20 \mathrm{mM}$ HEPES, $\mathrm{pH} 7.4,300 \mathrm{mM}$ sucrose, $50 \mathrm{mM} \mathrm{NaCl}$, $3 \mathrm{mM} \mathrm{MgCl}_{2}$, and $0.5 \%$ Triton-X100, for $4 \mathrm{~min}$ at $0^{\circ} \mathrm{C}$. After rehydration with $\mathrm{PBS}$, the cells were incubated for $10 \mathrm{~min}$ at $24^{\circ} \mathrm{C}$ with $3 \% \mathrm{H}_{2} \mathrm{O}_{2}$ in PBS containing $10 \mathrm{mM}$ glycine, $10 \mathrm{mg} /$ $\mathrm{ml} \mathrm{BSA}$, followed by blocking for $30 \mathrm{~min}$ with normal horse serum in PBS containing 1\% BSA. Goat anti-human PAR-2 polyclonal IgG antibody (N-19) (Santa Cruz Biotechnology) was added (1:100 dilution) for $2 \mathrm{~h}$ at room temperature. Cells 


\section{SUIT2}

A

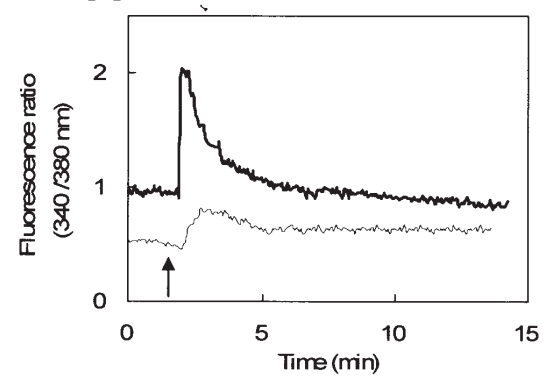

- Trypsin 10mM - Trypsin 1rM

D

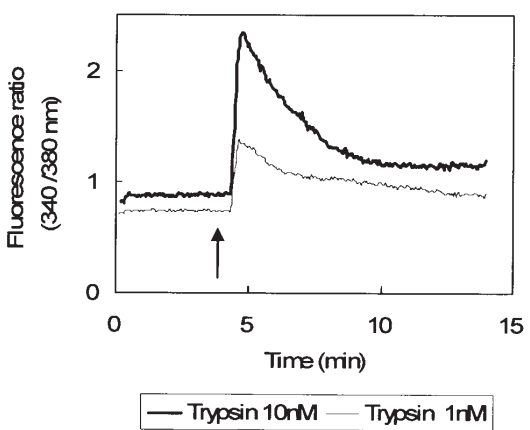

B

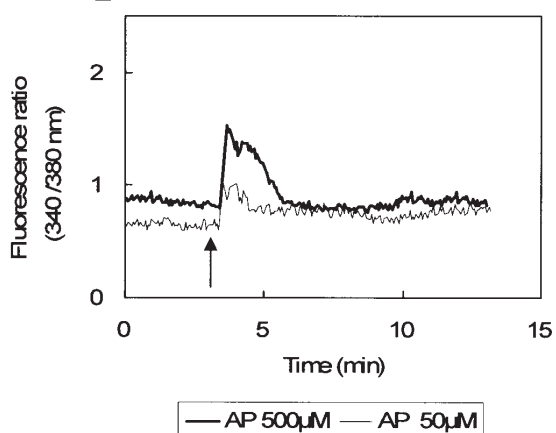

$\underline{\mathrm{MiaPaCa}}$

E

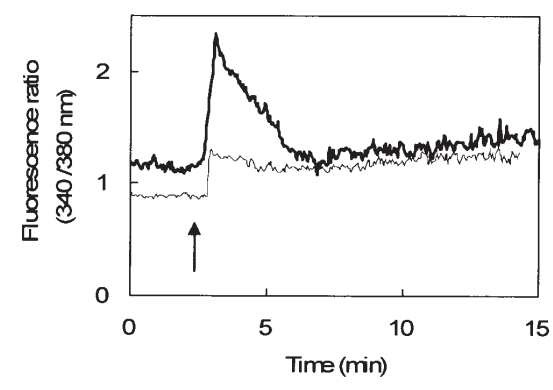

C

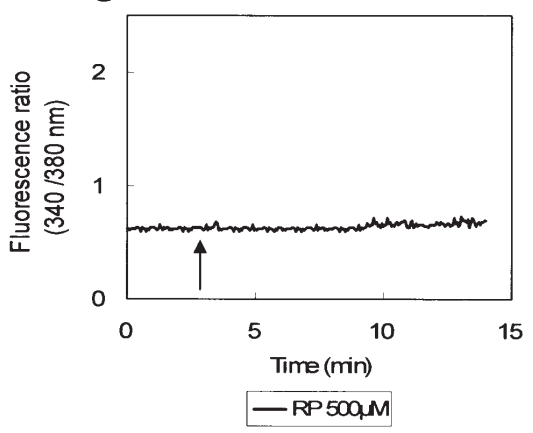

F

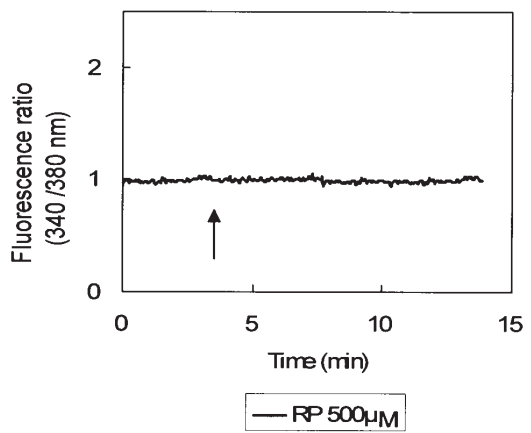

Figure 3. Effects of trypsin, PAR-2AP, and PAR-2RP on intracellular calcium mobilization. SUIT2 (A-C) and MiaPaCa2 (D-F) were challenged with trypsin, PAR-2AP, and PAR-2RP. Trypsin caused rapid increases in intracellular calcium transients in a dose-dependent manner in SUIT2 (A) and MiaPaCa2 (D). In the same way, PAR-2AP elicited rapid increases in intracellular calcium levels in SUIT2 (B) and MiaPaCa2 (E). However, PAR-2RP did not induce increases in intracellular calcium levels in SUIT2 (C) or MiaPaCa2 (F). The addition of trypsin, PAR-2AP, and PAR-2RP is indicated by arrows. The results of representative experiments are shown. Each experiment was replicated at least 3 times.

were washed 3 times for 10 min in PBS containing 1\% BSA and secondary antibody, FITC-labeled donkey anti-goat IgG (Santa Cruz Biotechnology), was applied for $45 \mathrm{~min}$ at room temperature.

Intracellular calcium measurement. Intracellular calcium concentrations of monolayers of pancreatic cancer cells were measured using the fluorescence indicator Fura-2/AM (Wako Pure Chemical Industries, Ltd., Osaka, Japan). The pancreatic cancer cells were seeded onto 10-mm glass-bottomed dishes (Matsunami Glass Industries, Ltd., Osaka, Japan) and cultured for 2 days. The cells attached to coverslips were then loaded with $5 \mu \mathrm{M}$ Fura-2/AM in HEPES-buffered saline $(135 \mathrm{mM}$ $\mathrm{NaCl}, 4.6 \mathrm{mM} \mathrm{KCl}, 1.2 \mathrm{mM} \mathrm{MgCl}{ }_{2}, 11 \mathrm{mM}$ glucose, $1.5 \mathrm{mM}$ $\mathrm{CaCl}_{2}, \mathrm{pH} 7.4$ ) containing $0.5 \%$ DMSO in the dark for $30 \mathrm{~min}$ at $37^{\circ} \mathrm{C}$. The cells were washed 3 times with HEPES-buffered saline before observation under an inverted fluorescence microscope. Fluorescence was measured with excitation at 340 and $380 \mathrm{~nm}$ alternately (every $2 \mathrm{sec}$ ) and emission at $510 \mathrm{~nm}$. The pancreatic cancer cells were stimulated by PAR-2 agonists, trypsin and PAR-2AP, and the ratio of the fluorescence at the two excitation wavelengths, which is proportional to $\left[\mathrm{Ca}^{2+}\right]_{\mathrm{i}}$ was calculated using the AquaCosmos version 1.20 imaging acquisition and analysis system for videomicroscopy (Hamamatsu Photonics K.K., Shizuoka, Japan).
ELISA. To study cytokine release by SUIT2 and MiaPaCa2, cells were stimulated with various concentrations of PAR-2 agonists. Cells were cultured for $24 \mathrm{~h}$ in suitable medium with $10 \%$ fetal calf serum (FCS). Cells were washed 3 times with PBS and cultured in the same medium for $8 \mathrm{~h}$ without FCS. Then, the cells were incubated in the same medium without FCS containing various concentration of PAR-2 agonists. After incubation for $24 \mathrm{~h}$ in medium containing PAR-2 agonists, the supernatants were collected and IL-6, IL-8, bFGF, TGF- 1 , and VEGF were detected by ELISA. For detection of all cytokines and growth factors, ELISA kits from BioSource Europe S.A. (Belgium) were used in accordance with the manufacturer's instructions. All data were calculated from 3 independent experiments and are presented as means \pm SE. Statistical significance of differences between means was determined using ANOVA. The Bonferroni correction was used for multiple comparisons. The confidence level of $\mathrm{p}<0.0033$ was considered significant. StatView ${ }^{\circledR}$ for Windows version 5.0 (SAS Institute Inc., Cary, NC, USA) was used for statistical analyses.

\section{Results}

The expression of PAR-2 was examined by RT-PCR, Western blot analysis, and immunocytochemistry in the following 
A

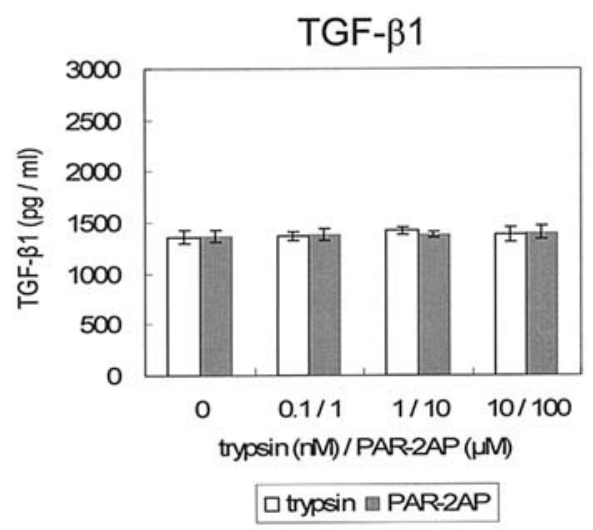

C

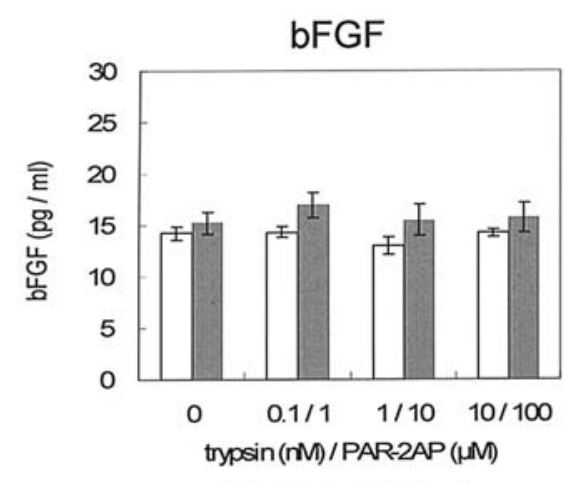

B

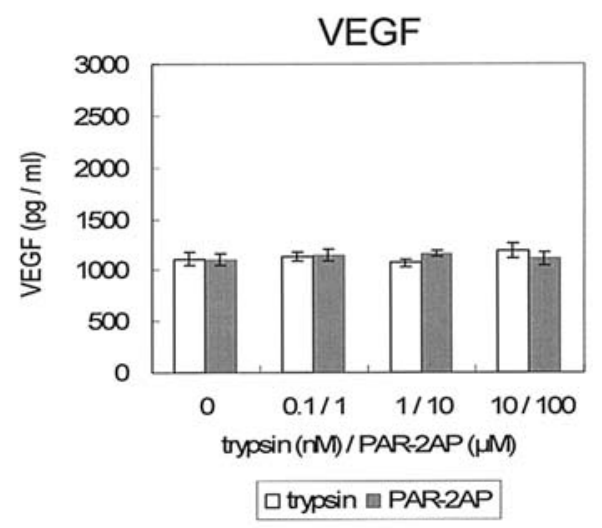

D

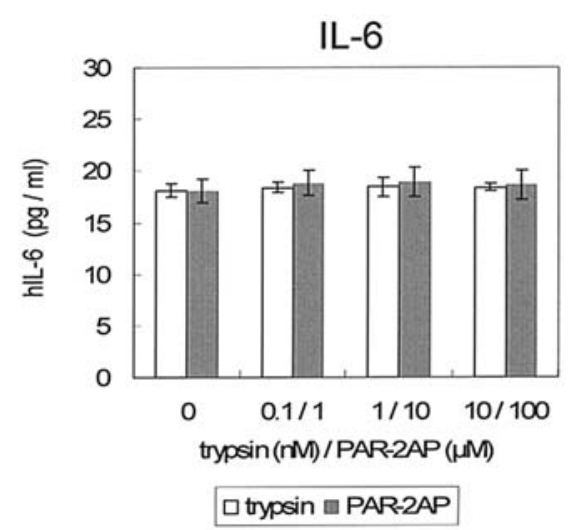

Figure 4. Effects of PAR-2 agonists on release of TGF-ß31, VEGF, bFGF, and IL-6 from MiaPaCa2. MiaPaCa2 cells were incubated in medium without FCS, which contained various concentrations of PAR-2 agonists. After incubation for $24 \mathrm{~h}$, the supernatants were collected and subjected to specific ELISAs for TGF-ß1, VEGF, bFGF, and IL-6. Neither trypsin nor PAR-2AP showed significant effects on release of TGF-ß1, VEGF, bFGF, or IL-6.

human pancreatic cancer cell lines: SUIT2, Panc1, MiaPaCa2, Capan1, and Capan2 (Fig. 1). The PCR product amplified with the PAR-2 primer set was detected at a size of $499 \mathrm{bp}$ in all 5 human pancreatic cancer cell lines. PAR-2 protein was shown to be localized to the cell surface of all human pancreatic cancer cell lines examined by immunocytochemical staining. However, the intensity of immunofluorescence was higher in SUIT2, Panc1, and MiaPaCa2 than in Capan1 or Capan2. Western blot analysis showed a PAR-2-specific band with the molecular weight of $55 \mathrm{kDa}$ in all 5 pancreatic cancer cell lines. However, Capan 2 expressed much lower levels of PAR-2 protein than the other cell lines. These observations almost paralleled those of immunocytochemistry. Moreover, we observed another band of approximately $50 \mathrm{kDa}$ in SUIT2 and Panc1 on Western blot analysis. The mouse anti-human PAR-2 monoclonal antibody (SAM11) used in the present study was raised against amino acids 37-50 (SLIGKVDGTS HVTG), which are located in the human PAR-2 cleavage site, this antibody can recognize not only full-length PAR-2 protein but also shorter PAR-2 protein cleaved by its agonists. Thus, the smaller band probably corresponded to cleaved PAR-2 protein. Fig. 2 shows the expression of trypsinogen detected by RT-PCR. PCR products amplified with trypsinogen primer sets were detected in SUIT2, which was found to have double bands on Western blot analysis using the mouse anti-human PAR-2 monoclonal antibody (SAM11), but only a single band was observed in $\mathrm{MiaPaCa}$. These data suggested that some pancreatic cancer cell lines produced trypsinogen, and activated PAR-2 in an autocrine manner.

Moreover, the PAR-2 signal is able to induce a rapid increase in cytosolic calcium concentration $\left(\left[\mathrm{Ca}^{2+}\right]_{\mathrm{i}}\right)$. SUIT2 and $\mathrm{MiaPaCa} 2$ were stimulated with PAR-2 agonists and intracellular calcium mobilization was determined to evaluate whether PAR-2 expressed on human pancreatic cancer was functional (Fig. 3). Human pancreatic trypsin and PAR-2activating peptide (PAR-2AP) corresponding to the tethered ligand of human PAR-2 was used. PAR-2 reverse peptide (PAR-2RP) was also used as a negative control. Stimulation of PAR-2 in SUIT2 and MiaPaCa2 by $10 \mathrm{nM}$ trypsin caused a rapid increase in the intracellular calcium transient. Under the same conditions, $1 \mathrm{nM}$ trypsin yielded a response similar to that seen at $10 \mathrm{nM}$. However, the peak of the curve was lower than that of $10 \mathrm{nM}$ trypsin (Fig. 3A and D). PAR-2AP also elicited a rapid increase in the intracellular calcium level, and the peak of intracellular calcium was higher with $500 \mu \mathrm{M}$ PAR-2AP than $50 \mu \mathrm{M}$ PAR-2AP (Fig. 3B and E). In contrast, PAR-2RP had no effect on calcium mobilization (Fig. 3C and F). These observations indicated that PAR-2 expressed on both SUIT2 and MiaPaCa2 was functional and was activated by PAR-2 agonists in a dose-dependent manner. 


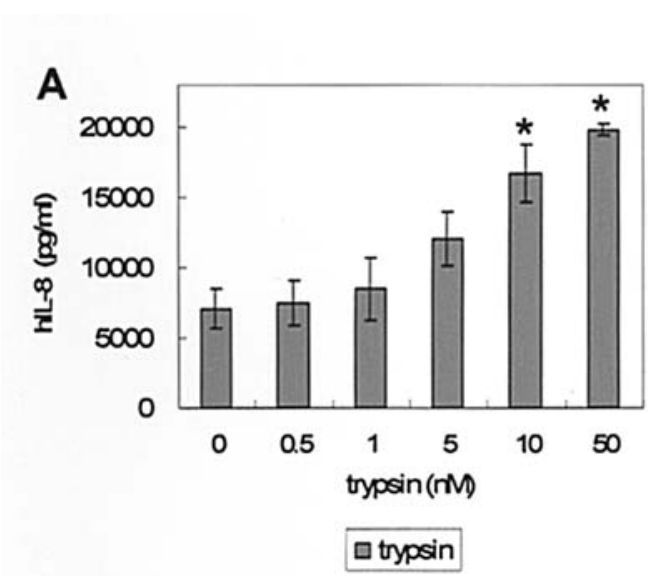

MiaPaCa2
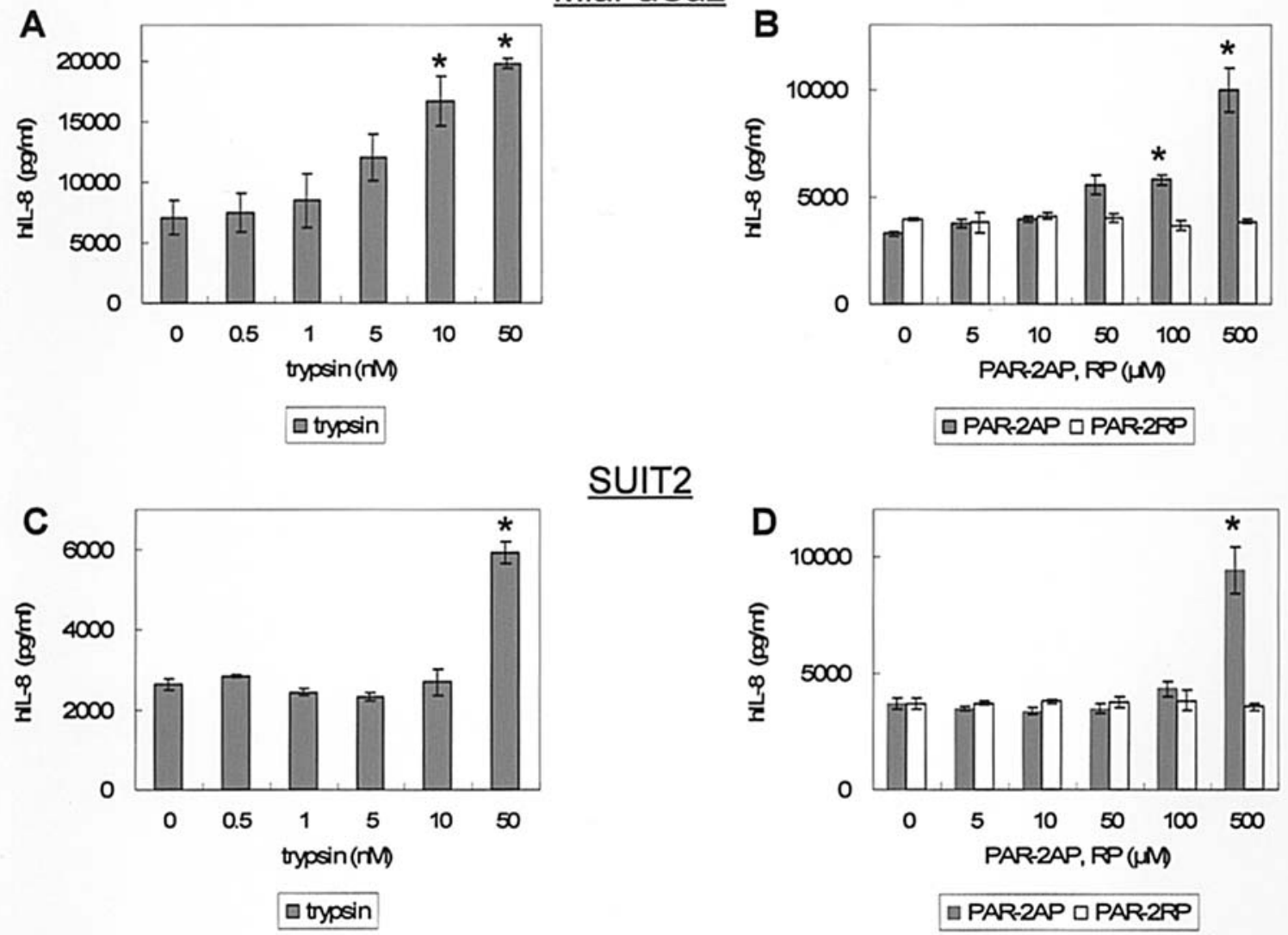

SUIT2

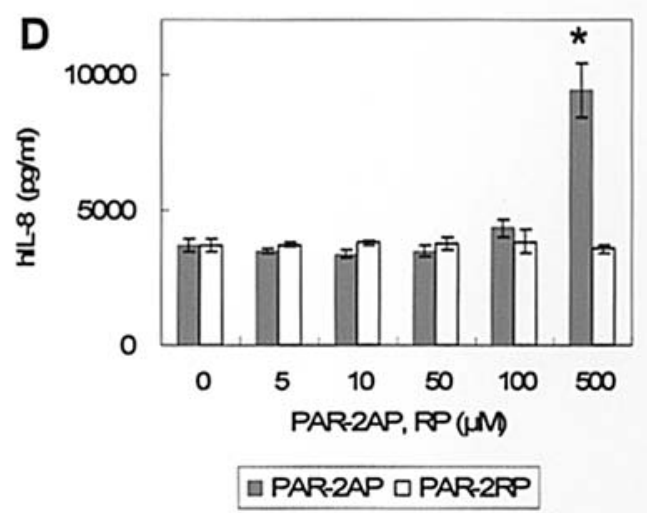

Figure 5. Dose-dependent up-regulation of IL-8 release by PAR-2 agonists. Both MiaPaCa2 and SUIT2 cells were incubated in medium without FCS, which contained various concentrations of trypsin, PAR-2AP, and PAR-2RP. After incubation for $24 \mathrm{~h}$, the supernatants were collected and subjected to specific ELISA for IL-8. Both trypsin and PAR-2AP up-regulated IL-8 release in a dose-dependent manner in MiaPaCa2 (A). On the other hand, no significant changes in IL-8 release from MiaPaCa2 were induced by PAR-2RP (B). In the same way, PAR-2 agonists up-regulated IL- 8 release, but PAR-2RP had no effect on IL-8 release from SUIT2 (C and D). All data were calculated from 3 independent experiments and are presented as means \pm SE.

The release of several growth factors and cytokines from MiaPaCa2 and SUIT2 stimulated by trypsin and PAR-2AP was examined. The culture supernatants of MiaPaCa2 and SUIT2 were collected at $24 \mathrm{~h}$ after stimulation by trypsin and PAR-2AP, and specific ELISAs were performed. Stimulation by trypsin and PAR-2AP had no significant effect on release of bFGF, VEGF, TGFb1, or IL-6 from MiaPaCa2 (Fig. 4). On the other hand, trypsin increased IL-8 release from MiaPaCa2 in a dose-dependent manner (Fig. 5A). At concentrations of $>10 \mathrm{nM}$, trypsin significantly up-regulated release of IL-8 from MiaPaCa2. At $50 \mathrm{nM}$, trypsin increased IL-8 release from MiaPaCa2 by about 3-fold as compared to the constitutive level. Moreover, another PAR-2 agonist, PAR-2AP, also up-regulated IL-8 release in the same way. In contrast, PAR-2RP had no effect on IL-8 release from MiaPaCa2 (Fig. 5B). In the case of SUIT2, the PAR-2 agonists, trypsin and PAR-2AP, significantly up-regulated IL-8 release from cancer cells in a dose-dependent manner, but PAR-2RP showed no effect on IL-8 release (Fig. 5C and D). These observations indicated that activation of PAR-2 resulted in up-regulation of IL-8 release from cancer cells.

In addition, we studied IL-8 receptor expression in SUIT2 and $\mathrm{MiaPaCa} 2$ and in the fibroblast cell lines MRC-5, MRC-9, and Wi-38 by RT-PCR with the specific primer sets for CXCR-1 and CXCR-2. Only CXCR2 was detected in both pancreatic cancer cell lines, SUIT2 and MiaPaCa2 (Fig. 6A). On the other hand, both CXCR1 and CXCR2 were detected in all 3 fibroblast cell lines, MRC-5, MRC-9, and Wi-38 (Fig. 6B), suggesting that up-regulated IL-8 from pancreatic cancer cells by the PAR-2 signal had an effect on the pancreatic cancer cells in an autocrine manner and on the fibroblasts in a paracrine manner.

\section{Discussion}

In the present study, we showed that PAR-2 was expressed in all 5 pancreatic cancer cell lines by RT-PCR, Western blot analysis, and immunocytochemical analyses. The measurement of intracellular calcium levels indicated that PAR-2 on the cancer cell surface was functional. On Western blot analysis, we observed double bands both of which were specific for PAR-2 in several cancer cell lines. In addition, trypsinogen expression was found in SUIT2, which had the double bands on Western blot analysis. These results support the hypothesis that some pancreatic cancers express a zymogen of trypsin and activate the PAR-2 in an autocrine manner. However, pancreatic cancer tissue has abundant trypsinogen, which has been shown to be activated into trypsin by micro-pancreatitis, infection, etc. These environments are peculiar to pancreatic cancer. Thus, pancreatic cancer 
A

pancreatic cancer cell lines

CXCR1 (583bp)

CXCR2 (501bp)
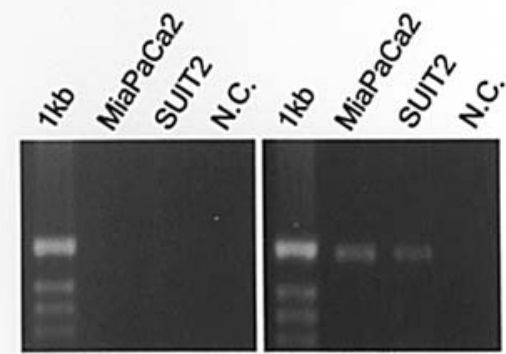

GAPDH
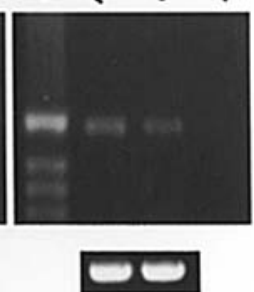

B fibroblast cell lines

\section{CXCR1 CXCR2}

(583bp) (501bp)

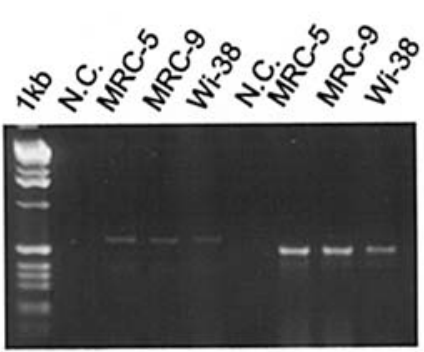

GAPDH

Figure 6. RT-PCR analysis of expression of IL-8 receptors, CXCR1 and CXCR2, in human pancreatic cancer and human fibroblast cell lines. The expression of IL-8 receptors in 2 human pancreatic cancer cell lines (A) and 3 human fibroblast cell lines (B) was analyzed by RT-PCR. Only CXCR2 was detected in both pancreatic cancer cell lines, and both CXCR1 and CXCR2 were detected in all 3 fibroblast cell lines. (A) lane 1, $1 \mathrm{~kb}$ DNA ladder; lane 2, MiaPaCa2; lane 3, SUIT2; lane 4, negative control. (B) lane 1, 1 kb DNA ladder; lane 2, negative control; lane 3, MRC-5; lane 4, MRC-9; lane 5, Wi-38.

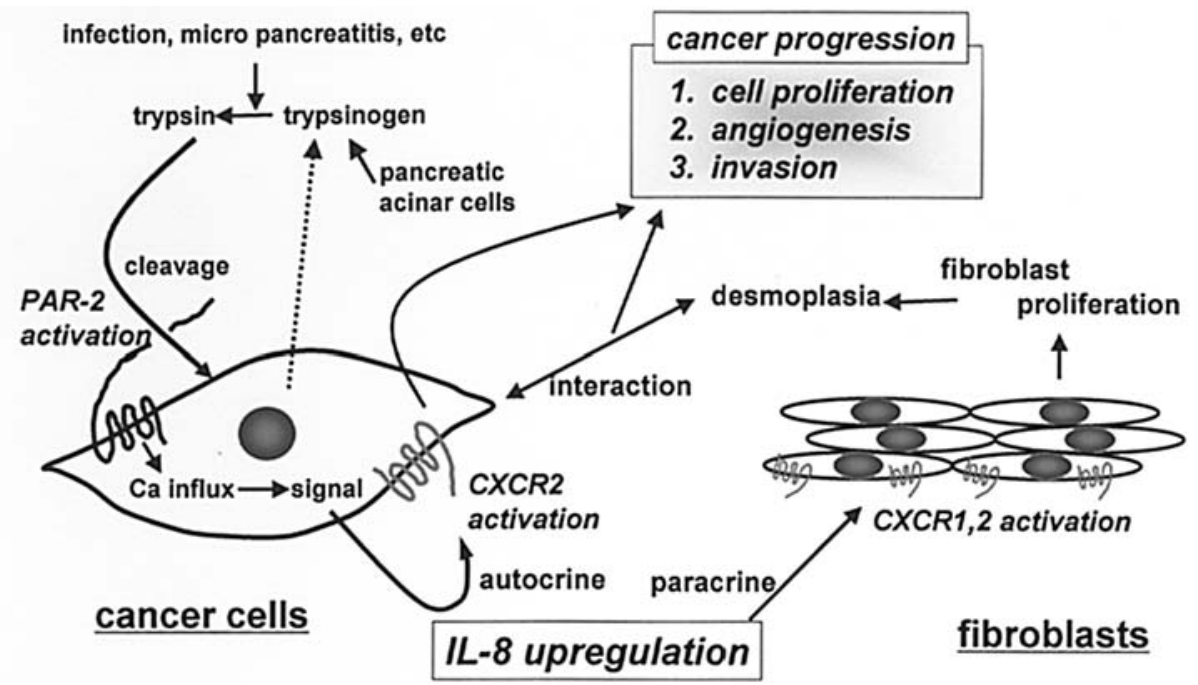

Figure 7. Signaling from PAR-2 could promote pancreatic cancer progression via IL-8 up-regulation. In pancreatic cancer, trypsinogen from pancreatic acinar cells can be activated to trypsin by a variety of mechanisms, such as infection and micro-pancreatitis. The trypsin thus produced cleaves and activates PAR-2 expressed on the pancreatic cancer cell surface. The signaling of PAR-2 up-regulates IL- 8 of pancreatic cancer cell origin. We proposed that the up-regulated IL-8 from cancer cells acts in an autocrine manner, resulting in cancer progression. Furthermore, we believe that the up-regulated IL-8 also acts on fibroblasts with CXCR, which are usually abundant in pancreatic cancer tissue, in a paracrine manner. Therefore, fibroblasts might proliferate resulting in fibrosis of pancreatic cancer. In this way, cancer progression can be promoted in a progressive manner by fibroblast-tumor interaction.

cells, with or without production of trypsinogen, might be constitutively activated by trypsin in pancreatic cancer tissues.

Next, we demonstrated that both trypsin and PAR-2AP significantly up-regulated IL-8 production from pancreatic cancer cells in a dose-dependent manner. We reported the detection of high levels of IL-8 mRNA in some human cancer cell lines and human cancer tissues, including gastric, colon, lung, gallbladder, breast, and pancreatic cancer $(23,24)$. Moreover, we showed previously that IL- 8 produced by the human pancreatic cancer cell line SUIT2 acted on itself and promoted cell growth (23). Other researchers have also reported this IL-8 autocrine-loop responsible for cell growth in pancreatic (25) and colon cancer (26). Furthermore, it was shown that IL-8 of cancer origin was involved in tumor angio- genesis in various types of cancer, including pancreatic cancer $(27,28)$. On the other hand, IL-8 has been shown to function as a motility factor for tumor cells, which may be relevant to tumor invasion and metastasis in many tumors $(29,30)$. It is widely accepted that IL-8 contributes to human cancer progression through these potential functions as a mitogenic, angiogenic, and motogenic factor. It has already been suggested that trypsin contributes to cancer progression by its classical ability to degrade various proteins, such as components of the extracellular matrix (ECM), and to activate matrix metalloproteinases (MMP) and serine proteases (31-35). In the present study, we showed that trypsin, which is released not only from pancreatic acinar cells but also from pancreatic cancer cells, is involved in cancer progression due to its 
novel ability to activate PAR-2 and up-regulate IL-8 release from pancreatic cancer cells.

Previously, we showed that there were significantly higher levels of expression of PAR-2 in pancreatic cancer tissues with severe fibrosis by immunohistochemical staining for PAR-2 on surgical specimens (21). We surmised that a signal of PAR-2 is involved in pancreatic cancer fibrosis. In the present study, we showed that the signal of PAR-2 led to IL-8 release from pancreatic cancer cells. IL- 8 produced by prostatic epithelial cells has been reported to be able to induce FGF2, a potent stromal and epithelial growth factor, from prostatic stroma (36). Stellate cells are widely believed to be involved in liver and pancreas fibrosis, which is characteristic of liver cirrhosis, chronic pancreatitis, and pancreatic cancer (37-39). Moreover, Gaca et al reported that stellate cells expressed PAR-2, and that PAR-2 agonists, mast cell tryptase, and PAR-2AP induced stellate cell proliferation and increased collagen synthesis by stellate cells (40). Although the mechanism of fibrosis in pancreatic cancer is still poorly understood, we proposed that there are at least two possible mechanisms by which trypsin induces fibrosis in pancreatic cancer: i.e. direct activation of PAR-2 of stellate cells and up-regulation of IL-8 of cancer cell origin. Fibrosis is one of the morphological hallmarks of several types of human tumor. Intratumoral fibrosis has been reported to be closely correlated with cancer progression and poor prognosis $(41,42)$. Moreover, several studies have indicated that matrix metalloproteinases, which play an important role in cancer invasion or metastasis, are expressed by fibroblasts with tumor-stromal interaction but not by the tumor cells or fibroblasts themselves $(43,44)$. IL-8 was also shown to be induced in non-small cell lung cancer and pulmonary fibroblast coculture (45). Previously, we showed that fibroblast-tumor interaction changes the constitutive expression of IL- 6 and IL- 8 in various cancer cell lines (46). Taken together, these observations suggested that intratumoral fibrosis contributes to cancer progression.

In the present study, we demonstrated that functional PAR-2 expression on pancreatic cancer cell lines, and the PAR-2 signal up-regulates IL-8 production in pancreatic cancer. Furthermore, the involvement of IL- 8 in the regulation of cancer and in induction of fibrosis has been reported in many previous studies. Taken together, these observations indicate that the up-regulated IL- 8 promotes cancer progression and induces fibrosis. The postulated significance of PAR-2 in pancreatic cancer progression is shown in Fig. 7. This mechanism should contribute to highly malignant potential and fibrosis of pancreatic cancer.

\section{References}

1. Nystedt S, Emilsson K, Wahlestedt C and Sundelin J: Molecular cloning of a potential proteinase activated receptor. Proc Natl Acad Sci USA 91: 9208-9212, 1994.

2. Vergnolle N: Review article: proteinase-activated receptors novel signals for gastrointestinal pathophysiology. Aliment Pharmacol Ther 14: 257-266, 2000.

3. Dery O, Corvera CU, Steinhoff M and Bunnett NW: Proteinaseactivated receptors: novel mechanisms of signaling by serine proteases. Am J Physiol 274: C1429-C1452, 1998.

4. Molino M, Barnathan ES, Numerof R, Clark J, Dreyer M, Cumashi A, Hoxie JA, Schechter N, Woolkalis M and Brass LF: Interactions of mast cell tryptase with thrombin receptors and PAR-2. J Biol Chem 272: 4043-4049, 1997.
5. Camerer E, Huang W and Coughlin SR: Tissue factor- and factor X-dependent activation of protease-activated receptor 2 by factor VIIa. Proc Natl Acad Sci USA 97: 5255-5260, 2000.

6. Nystedt S, Emilsson K, Larsson AK, Strombeck B and Sundelin J: Molecular cloning and functional expression of the gene encoding the human proteinase-activated receptor 2. Eur J Biochem 232: 84-89, 1995.

7. Saifeddine M, Al-Ani B, Cheng CH, Wang L and Hollenberg MD: Rat proteinase-activated receptor-2 (PAR-2): cDNA sequence and activity of receptor-derived peptides in gastric and vascular tissue. Br J Pharmacol 118: 521-530, 1996.

8. Bohm SK, Kong W, Bromme D, Smeekens SP, Anderson DC, Connolly A, Kahn M, Nelken NA, Coughlin SR, Payan DG and Bunnett NW: Molecular cloning, expression and potential functions of the human proteinase-activated receptor-2. Biochem J 314: 1009-1016, 1996.

9. Vergnolle N: Proteinase-activated receptor-2-activating peptides induce leukocyte rolling, adhesion, and extravasation in vivo. J Immunol 163: 5064-5069, 1999.

10. Vergnolle N, Hollenberg MD, Sharkey KA and Wallace JL: Characterization of the inflammatory response to proteinaseactivated receptor-2 (PAR2)-activating peptides in the rat paw. Br J Pharmacol 127: 1083-1090, 1999.

11. Kong W, McConalogue K, Khitin LM, Hollenberg MD, Payan DG, Bohm SK and Bunnett NW: Luminal trypsin may regulate enterocytes through proteinase-activated receptor 2 . Proc Natl Acad Sci USA 94: 8884-8889, 1997.

12. Corvera CU, Dery O, McConalogue K, Bohm SK, Khitin LM, Caughey GH, Payan DG and Bunnett NW: Mast cell tryptase regulates rat colonic myocytes through proteinase-activated receptor 2. J Clin Invest 100: 1383-1393, 1997.

13. Cocks TM, Sozzi V, Moffatt JD and Selemidis S: Proteaseactivated receptors mediate apamin-sensitive relaxation of mouse and guinea pig gastrointestinal smooth muscle. Gastroenterology 116: 586-592, 1999.

14. Kawabata A, Kuroda R, Nishikawa $\mathrm{H}$ and Kawai K: Modulation by protease-activated receptors of the rat duodenal motility in vitro: possible mechanisms underlying the evoked contraction and relaxation. Br J Pharmacol 128: 865-872, 1999.

15. Cocks TM, Fong B, Chow JM, Anderson GP, Frauman AG, Goldie RG, Henry PJ, Carr MJ, Hamilton JR and Moffatt JD: A protective role for protease-activated receptors in the airways. Nature 398: 156-160, 1999.

16. Miotto D, Hollenberg MD, Bunnett NW, Papi A, Braccioni F, Boschetto P, Rea F, Zuin A, Geppetti P, Saetta M, Maestrelli P, Fabbri LM and Mapp CE: Expression of protease activated receptor-2 (PAR-2) in central airways of smokers and nonsmokers. Thorax 57: 146-151, 2002.

17. Fiorucci S, Mencarelli A, Palazzetti B, Distrutti E, Vergnolle N, Hollenberg MD, Wallace JL, Morelli A and Cirino G: Proteinaseactivated receptor 2 is an anti-inflammatory signal for colonic lamina propria lymphocytes in a mouse model of colitis. Proc Natl Acad Sci USA 98: 13936-13941, 2001.

18. Miyata S, Koshikawa N, Yasumitsu H and Miyazaki K: Trypsin stimulates integrin alpha(5)beta(1)-dependent adhesion to fibronectin and proliferation of human gastric carcinoma cells through activation of proteinase-activated receptor-2. J Biol Chem 275: 4592-4598, 2000.

19. Darmoul D, Marie JC, Devaud H, Gratio V and Laburthe M: Initiation of human colon cancer cell proliferation by trypsin acting at protease-activated receptor-2. Br J Cancer 85: 772-779, 2001 .

20. Jikuhara A, Yoshii M, Iwagaki H, Mori S, Nishibori M and Tanaka N: MAP kinase-mediated proliferation of DLD-1 carcinoma by the stimulation of protease-activated receptor 2 . Life Sci 73: 2817-2829, 2003.

21. Ikeda O, Egami H, Ishiko T, Ishikawa S, Kamohara H, Hidaka H, Mita $\mathrm{S}$ and Ogawa M: Expression of proteinase-activated receptor-2 in human pancreatic cancer: a possible relation to cancer invasion and induction of fibrosis. Int J Oncol 22: 295$300,2003$.

22. Ohta T, Shimizu K, Yi S, Takamura H, Amaya K, Kitagawa H, Kayahara M, Ninomiya I, Fushida S, Fujimura T, Nishimura G and Miwa K: Protease-activated receptor-2 expression and the role of trypsin in cell proliferation in human pancreatic cancers. Int J Oncol 23: 61-66, 2003.

23. Ishiko T, Sakamoto K, Yamashita S, Masuda Y, Kamohara H, Mita S, Hirashima M and Ogawa M: Carcinoma cells express IL-8 and IL-8 receptor: Their inhibition attenuates the growth of carcinoma cells. Int J Cancer 6: 119-122, 1995. 
24. Sakamoto K, Masuda T, Mita S, Ishiko T, Nakashima Y, Arakawa H, Egami H, Harada S, Matsushima K and Ogawa M: Interleukin- 8 is constitutively and commonly produced by various human carcinoma cell lines. Int J Clin Lab Res 22: 216$219,1992$.

25. Miyamoto M, Shimizu Y, Okada K, Kashii Y, Higuchi K and Watanabe A: Effect of interleukin- 8 on production of tumorassociated substances and autocrine growth of human liver and pancreatic cancer cells. Cancer Immunol Immunother 47: 47-57, 1998.

26. Brew R, Erikson JS, West DC, Kinsella AR, Slavin J and Christmas SE: Interleukin-8 as an autocrine growth factor for human colon carcinoma cells in vitro. Cytokine 12: 78-85, 2000.

27. Shi Q, Abbruzzese JL, Huang S, Fidler IJ, Xiong Q and Xie K: Constitutive and inducible interleukin- 8 expression by hypoxia and acidosis renders human pancreatic cancer cells more tumorigenic and metastatic. Clin Cancer Res 5: 3711-3721, 1999.

28. Xie K: Interleukin-8 and human cancer biology. Cytokine Growth Factor Rev 12: 375-391, 2001.

29. Wilson AJ, Byron K and Gibson PR: Interleukin-8 stimulates the migration of human colonic epithelial cells in vitro. Clin Sci 97: 385-390, 1999.

30. Reiland J, Furcht LT and McCarthy JB: CXC-chemokines stimulate invasion and chemotaxis in prostate carcinoma cells through the CXCR2 receptor. Prostate 41: 78-88, 1999.

31. Koshikawa N, Yasumitsu H, Umeda M and Miyazaki K: Multiple secretion of matrix serine proteinases by human gastric carcinoma cell lines. Cancer Res 52: 5046-5053, 1992.

32. Stetler-Stevenson WG, Liotta LA and Kleiner DE Jr: Extracellular matrix 6: role of matrix metalloproteinases in tumor invasion and metastasis. FASEB J 7: 1434-1441, 1993.

33. Sorsa T, Salo T, Koivunen E, Tyynela J, Konttinen YT, Bergmann U, Tuuttila A, Niemi E, Teronen O, Heikkila P, Tschesche H, Leinonen J, Osman S and Stenman UH: Activation of type IV procollagenases by human tumor-associated trypsin-2. J Biol Chem 272: 21067-21074, 1997.

34. Okada Y, Gonoji Y, Naka K, Tomita K, Nakanishi I, Iwata K, Yamashita $\mathrm{K}$ and Hayakawa T: Matrix metalloproteinase 9 (92-kDa gelatinase/type IV collagenase) from HT 1080 human fibrosarcoma cells. Purification and activation of the precursor and enzymic properties. J Biol Chem 267: 21712-21719, 1992.

35. Imai K, Yokohama Y, Nakanishi I, Ohuchi E, Fujii Y, Nakai N and Okada Y: Matrix metalloproteinase 7 (matrilysin) from human rectal carcinoma cells. Activation of the precursor, interaction with other matrix metalloproteinases and enzymic properties. J Biol Chem 270: 6691-6697, 1995.
36. Giri D and Ittmann M: Interleukin-8 is a paracrine inducer of fibroblast growth factor 2, a stromal and epithelial growth factor in benign prostatic hyperplasia. Am J Pathol 159: 139-147, 2001.

37. Faouzi S, Le Bail B, Neaud V, Boussarie L, Bioulac-Sage P, Saric J, Balabaud C and Rosenbaum J: Myofibroblasts are responsible for collagen synthesis in the stroma of human hepatocellular carcinoma: an in vivo and in vitro study. J Hepatol 30: 275-284, 1999.

38. Haber PS, Keogh GW, Apte MV, Moran CS, Stewart NL, Crawford DH, Pirola RC, McCaughan GW, Ramm GA and Wilson JS: Activation of pancreatic stellate cells in human and experimental pancreatic fibrosis. Am J Pathol 155: 1087-1095, 1999.

39. Yen TW, Aardal NP, Bronner MP, Thorning DR, Savard CE, Lee SP and Bell RH Jr: Myofibroblasts are responsible for the desmoplastic reaction surrounding human pancreatic carcinomas. Surgery 131: 129-134, 2002.

40. Gaca MD, Zhou X and Benyon RC: Regulation of hepatic stellate cell proliferation and collagen synthesis by proteinase-activated receptors. J Hepatol 36: 362-369, 2002.

41. Hasebe T, Sasaki S, Imoto S and Ochiai A: Highly proliferative fibroblasts forming fibrotic focus govern metastasis of invasive ductal carcinoma of the breast. Mod Pathol 14: 325-337, 2001.

42. Hasebe T, Sasaki S, Imoto S and Ochiai A: Proliferative activity of intratumoral fibroblasts is closely correlated with lymph node and distant organ metastases of invasive ductal carcinoma of the breast. Am J Pathol 156: 1701-1710, 2000.

43. Uria JA, Stahle-Backdahl M, Seiki M, Fueyo A and Lopez-Otin C: Regulation of collagenase-3 expression in human breast carcinomas is mediated by stromal-epithelial cell interactions. Cancer Res 57: 4882-4888, 1997.

44. Noel A, Hajitou A, L'Hoir C, Maquoi E, Baramova E, Lewalle JM, Remacle A, Kebers F, Brown P, Calberg-Bacq CM and Foidart JM: Inhibition of stromal matrix metalloproteases: effects on breast-tumor promotion by fibroblasts. Int J Cancer 76: 267-273, 1998.

45. Anderson IC, Mari SE, Broderick RJ, Mari BP and Shipp MA The angiogenic factor interleukin-8 is induced in non-small cell lung cancer/pulmonary fibroblast cocultures. Cancer Res 60: 269-272, 2000.

46. Ishiko T, Mita S, Sakamoto K and Ogawa M: Fibroblast-tumor interaction changes constitutive expression of IL- 6 and IL-8 in human carcinoma cells. Int J Cancer 6: 639-645, 1995. 